\title{
Indigenismo, Antropología e Integración Nacional
}

\author{
POT JUan COMAS
}

El Alto Honor que el Consejo Universitario acaba de conferirme, a petición unánime de mis distinguidos colegas de la Facultad de Letras, al aceptarme como miembro del Cuerpo Docente de esta prestigiosa y cuatricentenaria Universidad es, dicho sea sin falsa modestia, excesivo y muy superior a los méritos que se me suponen, y que, con tanta gentileza como benevolencia, han sido sobrevalorados aquí, hace unos momentos, sobre todo por mi eminente colega y amigo el Dr. Luis E. Valcárcel. Consciente del limitado alcance de mis actividades científicas tengo sin embargo dos argumentos a modo de cautojustificación, por haber aceptado este inmerecido galardón. En primer lugar, el hecho de que desde 1940 estuve, y sigo, ligado directamente a las preocupaciones y problemas que el Perú siente y se planted, lem el terreng, antropológico e indigenista, y que son, en líneas generales, análogos a los que confrontan otros países latinoamericanos. En ese aspecto, ofrezco continuar $\mathrm{mi}$ entusiasta colaboración en la búsqueda de soluciones adecuadas, dentro siempre del modesto marco de mis posibilidades. En segundo término, considero que la honrosísima distinción de que he sido objeto, es, ante todo $y$ en gran parte, un homenaje a la también cuatricentenaria Universidad Nacional Autónoma de México a la que esoy directamente vinculado. En su nombre pues, tanto como en el mío propio, reitero a todos Uds. mi profundo agradecimiento.

El tema de mi conferencia se titula "Indigenismo, Antropología e Integración Nacional". Un somero examen demográfico de nuestra América, enfocado sobre todo desde el punto de vista cuantitativo de la población aborígen o indígena, si entendemos por tal en este caso concreto, a los descendientes y herederos blológicos Y culturales de los habitantes de América antes del siglo XV, nos 
ofrece un panorama heterogéneo que permite dividir a los distintos países en, por lo menos, cuatro grandes grupos. El primero comprende aquellas naciones donde no existe población aborigen, donde por circunstancias históricas se extinguieron al iniciarse la Conquista. En esie campo pueden incluirse por ejemplo Haití, República Domínicana, Cuba, Uruguay.

Un segundo grupo es el de aquellos países donde los pocos indígenas que quedan están ubicados en reservaciones; en lo que podríamos llamar un parque zoológico indígena. En ese caso están, por ejemplo, los Estados Unídos.

Un tercer grupo lo integran aquellas naciones donde la población aborigen forma minorías geográficamente marginadas, que tienen poca importancia dentro del contexto general demográfico del pais. En lo que ocurre por ejemplo en Venezuela, Costa Rica, Chile y Argentina.

Finalmente un cuarto grupo, el que realmente nos interesa aquí, constituido por aquellos países latino-americanos donde la población aborígen es mayoría absoluta o una minoría tan grande. que impone la necesidad de tenerla en cuenta al tratar de plantear y resolver con probalidades de éxito problemas socio-económicos y políticos en ámbito nacional. Es sobre todo el caso de México. Gutemala, Ecuador, Perú y Bolivia.

Por otra parte esta población indígena, refiriéndonos ahora más concretamente a los paises dondeles la Gran mayoría, a una minoría muy fuerte, sse puede dividie lèn dos categorías: el que podriamos llamar "sector selvícola", formado por grupos más o menos aislados, con poco contacto con la cultura "Occidental"; y, aquellos otros grupos más aculturados, que desde luego son más numerosos. La población indígena selvícola la forman básicamente los habitantes de las cuencas del Orinoco y del Amazonas; mientras que el grupo de población aculturadas en mayor o menor grado se localiza sobre todo, en México y Guatemala, asi como en el Altiplano Andino, es decir Ecuador, Perú y Bolivia. El enfoque que en cada caso tengan los problemas indigenistas, depende evidentemente de si nos referimos al seclor selvícola, o a los grupos ya en vías de aculturación.

En realidad puede parecer extemporáneo y anocrónico hablar en 1962 de "indigenismo", porque hace un cuarto de siglo que tuvo lugar en Lima una reunión interamericana al nivel Ministerial, donde se acordó la iniciación de un movimienti continental indigenista oficial, que dió lugar al Primer Congreso Indigentsta Intera- 
mericcino en Pátzcuaro (1940) y a los celebrados posteriormente en el Cuzco (1949), La Paz (1954) y Guatemala (1959). A 25 años de distancia podría pensarse que el problema solo tiene ya vigencia histórica. Sin embargo mi punto de vista es distinto. Una cosa es el planteamiento teórico reconociendo la existencia de un problema que alecta a la población indígena $y$ otra cosa es la realidad, la cuestión práctica en cuanto a métodos para mejorar esta población, para aculturarla, para integrarla a la respectiva nacionalidad. Y en ese terreno práctico, se observan una serie de divergencias, de diferencias, de antagonismos, que justifican la necesidad de insistir, por lo menos unos momentos, sobre el problema. ¿Es que exisle unanimidad, o por lo menos consenso mayoritario, en cuanto a que hay un problema que afecta la integración de nuestros paises?

1) Hay una orientación socio-política, que yo llamaría "occidentalista", aunque algunos la conocen más bien como "hispanista", que plantea el problema diciendo "estamos frente a grupos inferiores, frente a grupos de calidades distintas a la nuestra, que retrasan el progreso, que obstaculizan el avance del país, que son perezosos, que son dipsómanos, que toman caca o marihuana segun la región a que nos refiramos, que son incapaces de iniciativas; por tanto la única solución es eliminarlos, y que quede solamente el factor étnico occidental o europeo, que es el único capaz de hacer progresar el país" Esta actitud sé daba y se da. Escritores como José Ingenieros han afirmado ésto. Sociólogos como Oliveira Vianna en Brasil y "antropólogos como A.Posnacnsky en Bolivia lo han proclamado sin reparo?. Y aun actualmente, en la prensa y

1 Como testimonio históríco, de fines del siglo pasado. existe en el Perú un trabajo modelo de esta concepción racista:

Palma, Clemente. El porvenir de las razas en el Perú. Tesis de la Facultad de Letras. Imprenta Torres Aguirre. Lima 1897. $39 \mathrm{pp}$.

Ingenieros, José. Las razas inferiores. En: Crónicas de viaje, 1905-1906, pp. 161-172. Talleres Gráficos Argentinos. $\sigma^{\circ}$ edición. Buenos Aires, 1919.

Oliveira, Vianna, F. J.- Raça e Assimilaçāo. Tercera edición. Rio de Janeiro, 1938.

Oliveira Vianna,, F. J.- Populaçóes Meridionaes do Brasil. $4^{\circ}$ edición. Ría de Janeiro, 1938.

Posnansky, Arthur.- Khollas y Aruwakes, La Paz, Bolivia, 1942. Que es raza. Edición del Instituto Tihuanacu. La Paz, Bolivia, 1943. $52 \mathrm{pp}$.

Comas, Juan.- La discriminación racial en América. América Indígena, vol. 5, pp. 73-80 y 161-170. México, 1945. , Relaciones inter-raciales en América Latina: 1940-1960. Universidad Nacional Autónoma de México. 1961. $78 \mathrm{pp}$. 
en la calle, se constaia la existencia de fuertes sectores de opinión para los cuales nuestro problema--al decir nuestro me refiero a los cinco países antes nombrados- tendría fácil solución con la simple eliminación física de los grupos aborígenes, porque de este modo el progreso económico industrial, social, cultural,etc. del país se aceleraría grandemente al desaparecer el obstáculo que representan estos grupos étnicos inferiores, depauperados, incapaces, etc.

2) Frente a esta posición tenemos otra que puede calificarse de "indianista"; se trata de grupos poco numerosos pero activos que sueñan simple y llanamente con volver al pasado; reunidos en asociaciones de tipo más o menos chauvinista y demagógico añoran el pasado que pudieran representar Cuahulemoc o Alahualpa. Su lema es el rechazo de todo lo occidental; se trata de paises de abolengo indígena y hay que devolverles toda su prístina pureza; su meta sería volver al momento histórico de fines del siglo XV. Los "indianistas" tienen como pretexto, justificado en parte, la inicua explotación de que han sido objeto los grupos aborígenes durante 4 siglos. Es un argumentó innegable e irritable que les permite hablar de la opresión de los grupos "Occidentales", y a proponer como única posible solución el expulsar a los descendientes de los conquistadores.

No parece necesario hacer un análisis crítico ni negativo de estas dos posiciones extremas, tan falsa y errónea una como la otra. Quizá pudiéramós aćeptar que ambās tienen un contenido "político-filosófico", pero sin la menor realidad: los hechos muestran que en nuestros paises convivimos grupos etnicos que llamamos "europeos" y otros de tipo oborigen, indígena. Y como es utópico soñar con la eliminación física, radical, de uno u otro sector de población, no queda otra posibilidad que aceptar que la base de la integración nacional ha de ser la fusión biologica y cultural de los diversos grupos humanos que viven dentro de las fronteras de un pais.

3) Nos queda como tercera posición el llamado "Indigenismo" sobre el cual desde el punto de vista teórico ya todo se ha dicho. En las Actas Finales de los 4 congresos Indigenistas Interamericanos celebrados, repito, en México (1940), Cuzco (1949), La Paz (1954) Y Guatemala (1959) están especificados y aprobados por todos los gobiernos, de manera oficial, los Derechos de la Población Indígena y tambien naturalmente sus deberes, asi como la manera -teórica- de abordar su cumplimiento. Puede parecer entonces que basta con aplicar, con hacer efectiva, esta Carta del Indígena per- 
fectamente redactada y quiza incluso excesivamente detallada. Pero la dura realidad es que no se aplica; o que se oplica mal. Cabe entonces preguntarse, ¿por qué?; ¿Cuáles son las resistencias, pasivas $y$ activas al cumplimiento del Programa Indigenista aprobado oficialmente por todos los países interesados del Continente?. Se esgrimen pretextos, más o menos justificados en apariencia, con los cuales se obstaculiza la realización de unos postulados teórícos irrefutables.

\section{Veamos unos ejemplos:}

a) Se oyen afirmaciones tales como, "los indígenas se están extinguiendo; son grupos que paulatinamente desaparecen", "dejemos que pase una década, o quizá dos, y entonces no habrá ya problema indigenista"; por tanto no tenemos porqué pensar en soJuciones. Es decir se basan en el supuesto hecho demográfíco de que los pueblos indígenas se extinguen. Quizó alquien entre mis oyentes lo crea cierto pero he aquí dos informaciones concretas y actuales que prueban lo contrario y pueden aplicarse $\alpha$ todos los países.

En Bolivia, según el censo de 1950, había 1.901 .688 indígenas; en 1960 su número alcanzaba la cifra de 2.180 .738 ; y el cálculo para julio de 1962, hecho por el Departamento de Censos del Ministerio de Haciendo de Lo Pazces de 2.239.947 indígenas. Queda pues evidenciado que en ese pás hay aumento progresivo de la población aborígen?

En México, según manifestaciones recientes del Dr. Alfonso Caso, nuestra máxima autoridad en estas cuestiones y Director del Instituto Nacional Indigenista, "la idea de que la población indígena del país disminuye es falsa, al contrario, crumenta constantemente y manifiesta un espíritu de pronta superación" ${ }^{3}$. Estoy seguro que si se buscaran datos censales del Perú, Ecuador y Guatemala, observaríamós el mismo fenómeno. K el hecho está perfectamen. te justificado: el aumento de población debido a menor mortalidad por mejores condiciones ambientales no se encuentra contrarrestado por un fuerte proceso de aculturación espontánea, que permite

2 Datos obtenidos oficialmente del Departamento de Estadística y Censos del Ministerio de Hacienda de Bolivia, con fecha 18 de julio de 1962 .

s Publicado en la revista Tlempo, de Méxíco, correspondiente al día 26 de noviembre de 1982. 
equilibrar o aun disminuir el citado incremento demográfico. Es decir que el número de indígenas que culturalmente dejan de serlo, gracias al proceso natural espontáneo de aculturación, es insuficiente para compensar los índices cada vez menores de morbilidad y mortalidad entre los aborígenes. No cabe pues aceptar esta posición trente al problema indígena.

b) Hay también quienes, con erróneo criterio simplista, suponen que la solución del problema indígena es, para los indigenistas ,una cuestión de carencia de tierras; y rechazan tal premisa afirmando que en América hay tierras libres en exceso y que sólo se traia de legalizar su propiedad y ponerlas en cultivo. Aparentemente el hecho es cierto, ya que existen muchos millones de hecláreas de tierras nacionales que esperan colonización, y por tanto la contidad que puede corresponder a cada cabeza de familia es -en teoría- más que suficiente para asegurar su subsistencia. Pero el argumentu no resiste al mas somero análisis crítico. En primer término, el problema indigenista no es sólo -como veremos en seguida - un problema de falta de tierras; pero aun que así fuera, lo que deberían preguntarse nuestros contradictores sería: ¿cuál es la calidad y posibilidad de explotación inmediata de esas tierras nacionales que con tanta generosidad ceden a quienes carecen de ellas?. ¿en manos de quienes están las tierras fértíles de gran rendimiento agrícola o ganadero? ¿en qué cuantía? ¿cúal es la cantidad de tierras que, siendo potencialmente explotables, no se culivan poplrazones delintérés personal del latifundista, y en perjuicio evidente no sólo de las masas indígenas desposeídas sino también de la potencialidad económica del pcrís? La respuesta objetiva y desapasionada a estas y otras preguntas mostraría al más escéptico que únicamente una reforma agraria debidamente planeada y una redistribución de las tierras aprovechables solucionarían una parte del problema indígena. La colonización de las tierras nacionales, hoy selva, es una cuestión que rebasa al indigenismo entrando mas bien en los Planes Nacionales de mejoramiento económico. .

c) Hay también quienes niegan la existencia de un problema indigenista por cuanto "es imposible o extremadamente difícil determinar a quien debe considerarse indígena"; en consecuencia si falta el actor no puede haber acción... - - Pero el argumento es ficticio; existen numerosas fuentes informativas que ofrecen una definición clara y realista del "indio"; nos basta con recordar aquí 
los nombres de A. Caso, Manuel Gamio y J, de la Fuentet, e insistir en el hecho de que a los indigenistas no les interesa en lo absoluto el criterio biológico o racial para definir y delimitar su área de actividades; consideramos "indígenas" a quienes poseen predominio de características de cultura material y espiritual peculiares y distintas de las que hemos dado en denominar "cultura occidenta! o europea"; podrán ser somáticamente indígenas, o ser mestizos que por circunstancias ambientales se adaptaron $\alpha$ través de varias generaciones a las costumbres y modos de vida del grupo aborígen con quien conviven. Para el indigenista todos estos sectores de población son "culturalmente indígenas" y por tanto entran en el campo de sus preocupaciones e intereses. Se nos dirá que resulta difícil, y en ocasiones altamente subjetivo, determinar los casos - límite de inclusión o exclusión; es cierto, pero ello no significa que deba soslayarse ni olvidarse el problema, sį̣o simplemente que no es de fácil planteo en determinadas circunstamcias.

d) Como recurso supremo para anular toda posible efectividad del movimiento indigenista se ha dado en tildarle de "comunista", con lo cual naturalmente se aspira a crear un ambiente hostil que convierta en anti-indigenistas a muchas gentes poco interiorizadas en estos problemas y afectas a dejarse sugestionar por un marbete que, en lasúltimas décadas, ha adquirido peligroso sentido. Es el crgumento solapado de quienes conscientemente tratan de confundir una doctrina polffica con reivintaicarciones de justicia social; se trata del sector ultraconservador $y$ tradicionalista de cada uno de nuestros países, para quienes es "comunista" quien favorezca el reajuste socio-económico de las masas aborígenes, ya que ello habrá indudablemente de lesionar algunos de sus privilegios de casta, a todas luces injustos. Como ejemplo basta recordar que el Gobierno de uno de los países latinoamericanos que suscribió oficialmente el Acta Final del Congreso Indigenista de Patz-

4 Caso, A.- Definición del indio y lo indio- América Indígena, vol, 8, pp. 239-247. México, 1948.

Gamio, Manuel. La identificación del indio. América Inclígena, vol. 6. pp. 99-103. México, 1946.

Fuente, Julio de la.- Definición, pase y desaparición del indio en México. América Indígenista, vol. 7, pp. 63-69. México, 1947.

También el Acta final del Congreso Indgenista Interamericano del

Cuzco (1949).
Comas, Juan.- Ensayos sobre indigenismo, pp. 225-240. México, 1853. 
cuaro, México (1940) donde se establecía la creación del Instituto Indigenista Interamericano, no ratificó dicho documento durante varios años, debido a que un influyente sector político del país habia propagado la idea de que se trataba de un organismo revolucionario, "comunista", y por tanto que no se debía contribuir a su sostenimiento. Fue necesaria una lenta labor para lograr que ese Gobierno ratificara la Convención de Patzcuaro, reconociendo que la labor del 1.1.1. y de todo el movimiento indigenista continental no tuvo nunca, ni en sus comienzos ni en la actualidad, nada que ver con una determinada doctrina política: expropiación $\mathrm{y}$ redistribución de latifundios, participación obrera en los beneficios de empresa, trabajo agrícola en cooperativas o en comunidad, nacionalización de las riquezas del subsuelo, etc., son principios de mejoramiento social acepiados por una gran mayoría de paises y nada tienen que ver con el fantasma del "comunismo". Recordemos en fin unas expresiones del gran indigenista Manuel Gamio, que en su calidad de Director del 1. 1. I. salía al paso de esta campaña de desprestigio aludiendo a que ciertas facciones políticas,

"atribuyen al Instituto, con buena fe equivocada, con ceguera o con malicia, esta o aquella bandera e indistintamente pretenden marcar nuestras actividades con uno un otro menbrete partidista".

Y añadía que el Instituto tan alejado del comunismo como del nazi-facismo,

"aspira en esentia lacque se formblice el deficiente desarrollo biológico del indígena, mejoren efectivamente las inferiores condiciones económico-culturales en que desde hace tiempo vegeta, se respete su personalidad y tradición y sean abolidos los abusos de quienes a espaldas de la Ley a escudandose en ella cuando es inadecuada, lo maltratan, explotan y esclavizan".

Terminando con esta frase:

"Esta es la política sin menbrete del apolítico Instituto Indtgenista Interamericano, el cual estamos seguros que prefería desintegrarse y desaparecer antes que desvirtuarla en lo mas mínimo" ".

5 Gamio, Manuel- La Política de una Institución no política. América Indigrena, vol. 4, pp. 179-182. México, 1944.

Comas, Juan.- Razón de ser de] movimiento indigenista. América Indigena, vol. 13 , pp. 133-144. México, 1953. 
e) En último término debemos referirnos a la opinlón de ciertos investigadores y estudiosos de los problemas sociales que consideran la cuestión indígena como resultado exclusivo "de un desajuste económico y social". La tesis es de una gran importancia porque la estimo una "verdad a medias" y por tanto peligrosa en su interpretación. Cierto que el mejoramiento indígena implica una cuestión socioeconómica que no solo no puede olvidarse sino que es indispensable tener en cuenta; pero al mismo tiempo, es decir simultáneamente, precisa atender el factor cultural que tiene carác ter diferencial, para justificar precisamente la existencia de un problema indigenista. Los desajustes socio-económicos de ciertos estratos sociales se presentan en todos los países, o en la gran mayoría de ellos, y sin embargo no se habla de "indigenismo". Ello se debe -creemos nosotros- precisamente a que falta en tales casos la heterogeneidad cultlral peculiar en las naciones latino-americanasa a que nos estamos refiriendo. Hacemos hincapié en este punto por estimarlo fundamental en nuestro planeamiento. Sin culturas distintas no existiria, no tendría razón de ser, un movimiento indigenísta; el dinero no basta para resolver el problema indígena (aunque sin dinero tampoco es posible hacerlo); y tenemos - por desgracia - muchos ejemplos de ensayos fallidos precisamente por no haberse tenido en cuenta, en primer término, el hecho de la coexistencia de culturas distintasey la necesidad de un proceso de aculturación. A modo de eiemplo recordaremos algunas experiencias concluyentes, demostrando que el mejoramiento higiénico y sanitario en grupos indígenas únicamente resulta eficaz y decisivo cuando se tiene en cuenta el factor cultural. El primer caso se refiere al establecimiento de un Programa Higiénico-sanitario en la reservación de indios Navaho del sur de Estados Unidos; la Dra. Leighton demostró no solo la previa necesidad de conocer lars costumbres y creencias de los Navaho en cuanto a las enfermedades y su curación, sino también la absoluta exigencia de contar con la "cooperación y colobaración de los curanderos y shamanes si se desea lograr que se adopten paulatinamente práctlcas médicas científicas" ". A las mismas conclusiones llegó el Dr. Pijoan entre los indios Moskito de Nicaragua y a colaborar en un "Programa

* Leighton, Dorothea C.- El indio y la medicina. América Indjgena, vol, 3, pp, 127-133. México, 1943. 
de Entrenamienio de indígenas, incluyendo curanderos, en prácticas sanitarias y medicinales de carácter rudimentario" 7 .

Muy recientemente, al efectuar una evaluación acerca de las deficiencias del programa de asislencia médica e higiénica en la base de Pillapi (Bolivia) a cargo de Acción Andina, dice el Antropólogo H. Marlínez: "en la mayoría de los casos se debe a motivaciones de orden cultural" 8 .

En cuanto al mejoramiento agrícola podrían repetirse los casos en que por olvido del factor cultural (costumbres y creencias en torno a las prácticas de preparación de la tierra, de siembra, de cultivo y de recolección) los resultados obtenidos fueron nulos o muy inferiores al esfuerzo realizado.

En el terreno educatico basta referirnos al idioma materno, como rasgo cultural. En muchas de las campañas de alfabetización del indígena en castellano, como idioma nacional, se olvidó -consciente o inconscientemente- la lengua aborigen, tratando de castellanizar directamente; en apariencia la solución es fácil y desde luego así se soslaya la dificultad de encontrar maestros bilingües para cada uno de los numerosos idiomas hablados en las comunidades indígenas. Pero la realidad es que el sistema no ha sido un éxito. Múltiples experiencias realizadas en muchos páses donde eI idioma nacional es distínto a la lengua materna ha puesto en evidencia que desde el punto de vista didáctico es más rápido y eficaz el método del bilinguisine que el directo. En América contamos en ese terreno conoung experièneigi rnuynvaliosa puesta en práctica en diversos países (México. Guatemala, Ecuador, Perú, Bolivia) por el Instituto Lingüístico de Verano, con sus Cartillas bilingües y la preparación de Promotores y maestros selvícolas que castellanizan a sus Comunidades con base en su idioma materno.

Este es un punto en el que deblera ya haberse llegado a uniformar el criterio pedagógico: pero desgraciadamente no es así. Mantenemos la heterogeneidad de actuaciones y mientras en ciertas zonas escolares rurales se ha adoptado el método bilingüe para. la castellanización, en otras se intenta todavía lograrlo en forma directa. No cabe detallar aquí los argumentos en pro y en contra.

7 Fijoan, Michael,- The Miskito Indians. América Indígena. vol. 4 , pp. 255-263. México, 1944. Boletín Indigenista, vol. 4, pp. 118. Mé-
xico, 1944.

Martinez, Héctor

Lima, 1561. (Estudio realizadormedad y medicina en Pillapi. p. $25 .-$ ménez, Consultor de la ción Andina). 
así como los resultados obtenidos con uno y con otro sistema; únicamente podemos asentar la afirmación, basada en la práctica escolar, de que es imprescindible tener en cuenta el idioma materno, como rasgo cultural, en cualquier ensayo de aculturación indígeno ${ }^{9}$.

El dominio del castellano es evidentemente necesario en todo proceso de integración nacional, pero ello no implica la eliminación y extinción forzosa de los idiomas aborígenes. ¿Es que hace falta que desaparezcan el quechua o el aymara para que haya Peruanidad? ¿Es que es necesario que desaparezcan el maya y el azteca para que haya Mexicanidad? Mi respuesta es no; definitivamente No. Se puede saber y utilizar el castellano, y mantener al mismo tiempo el idioma materno si los interesados quieren conservarlo; pero tampoco obligándolos a que lo utilicen. Tratándose de idiomas que hablan un reducido número de personas, como el Seri en México, evidentemente no hay problema, ya que se extinguirá por si solo. Pero cuando los hablantes se cuentan por centenares de miles, o por millones, el problemt cultural juega un papel definitivo en ese aspecto de la integración porque - reiteramos- está demostrado pedagógicamente que el bilingüismo es la mejor forma de enseñar el idioma nacional a través del materno.

Es un hecho de observación que con el tiempo dos grupos étnicos en contacto modifican parcialmente sus patrones de vida, material y espiritual; enl formas que drarian cuantitatiya y cualitativamente segúu las condiciones deicador caso; es el llamado proceso de aculturación expontánea, a que nos hemos referido en un principio, pero cuya acción no es lo suficientemente intensa para compensar el incremento demogrático. Es decir que la aculturación expontanea no coadyuva mas que en mínima parte al proceso de integración de la nacionalidad.

Por otra parte, esta aculturación espontánea, al azar, motiva preconfrecuencia los rasgos culturales que se asimilan no son los mejores. No se trata de un proceso sistemático que previamente haya investigado cuales son los rasgos culturales que se considera necesario cambiar y cuales otros, por el contrario, deben conservarse y aún intensificarse; es decir hace falta la aculturación dirigida.

- Unesco. Empleo de las lenguas vernáculas en la enseñanza. Monografías sobre Educación Fundamental. París, 1954. $162 \mathrm{p}$.

Comas. Juan, - La lengua vernácula y el bilingüismo en la educación. América Indígena, vol. 16, pp. 93-109. México 1956. 
La higiene y la salubridad en relación con las prácticas de brujería y de shamanismo, ofresen un claro ejemplo al respeto: hace unos momentos un distinguido colega me contaba el hecho de que entre ciertas comunidades indígenas del Perú, y para curar determinadas dolencias, se administram al enfermo partículas arrancadas de los petroglifos llamados quilcas. Esta sería sin duda una práctica que debería eliminarse ya que no es beneficiosa y sí desde luego nociva para quien se somete a ella. Pero junto a éste se conocen otros muchísimos ejemplos de medicación aborigen, por brujos y hechiceros, en los que se recurre a la acción de determinadas plantas cuyos principios curativos han sido posteriormente reconocidos por la Química y la Farmacología e incorporadas a la Terapéutica "occidental". En la mente de todos Uds. están ejemplos en ese terreno 10; de ahí la ineludible necesidad de no rechazar. ni tampoco aceptar, en su totalidad las prácticas aborígenes en torno a la salud y a las enfermedades; en cada caso procede el cuidadoso examen selectivo de lo que debe eliminarse y de lo que conviene conservar.

Lo mismo cabrio plantear en el terreno del arte indigena (textiles, cestería, cerámica, orfebrería, etc.), si bien en este caso, más que en ningún otro, existe amplia coincidencia en aceptar que es un rasgo cultural, de índole material y psíquica, cuya conservación y mejoramiento debe fomentarse sin la menor duda.

Estamos discurriendootacen el Campot de Ia Antropología o ciencia que estudia al hombre (Antropolopía física) y su cultura en sus diversas manifestaciones, agrupadas mas o menos convencionalmente en Etnología, Arqueología, Lingüistica, Folklore, etc. Todo ello formando una unidad lo cual estimo de la mayor importancia señalar ya que no cabe pensar en una Antropología fragmentada, por el hecho de que sus métodos y finalidades sean aparentemente heterogéneos; el objetivo a largo plazo es el mismo para todas las ciencias antropológicas: en nuestro caso el cabal conocimiento de los grupos aborígenes. Desde el punto de vista biológico ocupa el Perú una situación privilegiada en torno a la "fisio gía de hombre del altiplano" que, en un $90 \%$ de casos, es indígena. $Y$ en el aspecto cultural se impone --como conclusión de todo

J0 Comas, Juan.- La influencia indígena en la Medicina Hipocrática en la Nueva España del Siglo XVI. América Indígena, vol. 14. pp. 327-j61. México, 1954.

Comas. Juan. La enseñanza de la Antropología y la utjlización de a la cultura universal. Amériea Indígena, vol. 17, pp. 39-85. México, 1957. 
lo expuesto- el previo coocimiento de los diversas culturas aborigenes para aplicarlo al proceso de integración. Integración es el concepto esencial que debe normar en todo ensayo de aculturación dirigida; justo es recordar, por lo que se refiere al Perú, la valiosa realización que representa el Sistema de Núcleos Escolares establecidos desde 1946 en Cuzco y Puno como resultado del Convenio de Arequipa, entre Bolivia y Perú suscrito el $1^{0}$ de noviembre de 1945 por los Ministros de Educación de ambos países; lo era en esa época del Perú nuestro distinguido colega, antropólogo e indigenista, Dr. Luis E. Valcárcel a quien debe acreditarse el mérito de tan plausible iniciativa. El criterio de integración fue claramente expresado en esa oportunidad al afirmarse "que el problema indígena es de índole sacial, económica, sanitaria, víal, agraria, educacional, jurídica, etc. a cuya solución deben concurrir con sus mejores esfuerzos todos los organismos de ambas Repúblicas" "11. De la acertada aplicación de este principio dependía el éxito o el fracaso en la tarea de incorporación de las masas indígenas a la vida nacional.

HaY que mencionar también la labor del Instituto Indigenista Peruano, fundado en 1946 y ampliado con la creación de un Consejo Técnico (Decreto Supremo de 7 de noviembre de 1956), "encargado de efectuar directamente, o en colaboración de otras entidades nacionales o misiones de carácter internacional, estudios científicos relacionadosiconilos problemas socio-económicos de las comunidades indígenas $y_{0}$ núcleos compesinos" así como "efectuar experimentos de Antropología aplicada.... programas de promoción social, económica y cultural, etc." Aunque quizá no ha dado todo el rendimiento que podría esperarse de su acertada orientación, debido a escasez de financiamiento. Organismos similares, trabajando en favor de la aculturación integral de los aborígenes, funcionan en otros países latino-americanos, como son México, Guatemala, Brasil, Bolivia.

También en ámbito continental y con éxito cada día crecien. te, está el Instituto Lingüístico de Verano, que mediante convenios bilaterales con los respectivos gobiernos viene realizando una eficaz labor de aculturación. En Perú, desde 1945, trabaja entre más de 29 grupos de la selva amazónica, no sólo en el aprendizaje

11 Informe sobre los incicleos escolares: 1946-1958. Servicio Cooperativo Peruano-norteamericano de Educación. Ministerio de Educación Pública. Lima, 1959.- $124 \mathrm{pp}$. 
de didiomas y preparación de cartillas para castellanización con el sistema bilingüe, sino también en el entrenamiento de promotores y maestros indígenas bilingües, ayuda en mejoras técnicas agrícolas e introducción de nuevos cultivos, práclicas de higiene familiar y comunal, servicio médico preventivo y curativo, etc.

En los 3 páses del altiplano andino se ha establecido desde 1954 la llamada Misión Andina (actualmente Acción Andina) co. mo resultado de la colaboración de cada uno de los gobiernos con la Organización de las Naciones Unidas (ONU) y cuatro de sus instifuciones especíalizadas (Unesco, FAO, OMS y OIT), en un esfuerzo conjunto para "arrancar a las poblaciones indigenas de los Andes de la miseria y exploiación en que vivían hasta entonces $y$ en que siguen viviendo todcvía en gran medida"; se trata "de una aplicación sistemática del llamado método integral tendiente a promover la integración de las poblaciones aborígenes". Cada base de acción cuenta con un equipo formado, generalmente. "por un jefe, un agrónomo, un médico, un especialista en educación, un veterinario, una enfermera, una comadrona, algunos instructores en materia de formación profesional y artesanal, etc." 12. No se trata de hacer aquí la evaluación de los resultados abtenidos en estos proyectos; nos basta, por una parte, con mos* trar como resalta el criterio de integralidad en la acción programada, y por otro la carencia de un antropólogo entre el personal técnico seleccionado.loteca de Letras

Mas recientementeP EcuadorlliBoliviaeys Berú han establecido, bajo distintos nombres, planes nacionales de integración: Campaña Nacional de Integración del Campesino (Ecuador, 27 de mayo de 1961), Departamento para el Desarrollo de la Comunidad Ru. ral y Plan Nacional de Desarrollo Rural (Bolivia, 25 de noviembre de 1960), Comisión del Plan Nacional de integración de la población aborigen (Perú, 17 de diciembre de 1959). Todos ellos, por lo menos teóricamente, tralan de abarcar todos los intentos y ensayos de mejora de las comunidades indígenas con el objetivo de lograr la plena integración de tales grupos a la respectiva nacionalidad.

Ahora bien no siempre, ni en todos los casos, se ha tenido en cuenta en la puesta en marcha de los planes integrales de mejora-

12 Misión Andina en el Ecuador: 1956-1961, Documento 61/2 de la Oficina de Misión Andina en Quito. Sin fecha. $46 \mathrm{pp}$.

Rens, Jef. El programa Andino. Oficina Internacional del Trabajo. Ginebra, 1961 - 50 pp. 
miento y acumulación indígena el papel que debe desempeñar al antropólogo. Ya señalamos hace breves momentos la carencia de antropólogo entre el personal de expertos previsto en los proyectos organizados por Misión Andina. Pero podemos ofrecer otro ejemplo más reciente; se anuncia que a partir de $1^{\circ}$ de enero 1963 funcionará en Perú una Misión Asesora del Instituto Nacional de Planeamiento; pues bien entre los 20 expertos previstos $y$ específicamente designados hay 1 educador, y 1 sociólogo, pero ningún antropólogo ${ }^{13}$. LSe trata de un simple olvido subsanable?. Lestamos por el contrario ante un caso de desconocimiento del problema y más aún del papel que el antropólogo puede y debe desempeñar en todo intento de integración nacional en países con grupos de población culturalmente heterogéneos?

La experiencia de muchos años en México, y los desacierios cometidos en un principio, permiten afirmar que sin el Antropólogo estos proyectos serán un fracaso o por lo menos rendirán frutos de mucha menor cuantía y desproparcionados a los gastos que irroguen. Esto explica el porqué, por ejemplo, el Ministerio de Recursos Hidráulicos de México tuvo durante muchos años una Comisión de Antropólogos para asesoramiento en cuanto al modo de desplazar con éxito a la población indígena de la región que iba a ser cubierta por la represa del río Papaloapan; y la presencia de un antropólogo en el Instituto Nacional de la Vivienda; y de otro en el Inslituto Mexicano delcSeguro Socialiete.

No pensamos ni jpor un momento que el antropólogo sea la panacea universal en este tipo de actividades socioeconómicas; y menos aún que el antropólogo deba ser el director o jefe de los equipos de trabajo. Pero sí creo que debe contarse con su asesoramiento obligatorio, con su consejo, $y$ tenerse muy en cuenta sus sugestiones para ver la mejor forma de aplicar las técnicas agricolas, sanitarias, educativas, etc. de acuerdo con el material humano de que se trate.

En sintesis, considero que la justa aspiración de nuestros paises por lograr en breve plazo una verdadera integración nacional ( $y$ teniendo en cuenta la realidad de la existencia de un mosaico racial y cultural) no puede llevarse a cabo en forma sistemática y eficaz si no se conocen previamente estas culturas y se delerminan concretamente los alcances cuantitativo y cualitativo que de-

13 Datos publicados en El Comertio, de Lima, del día 26 de noviembre de 1962 . 
ba darse al proceso de aculturación. Y esa actividad le correnponde al Antropólogo.

Llegamos así a la lógica conclusión de que es necesario, mas bien diríamos que imprescindible, en nuesiros países, la adecuada organización y sistematización de la enseñanza de la Antropologia, considerada en su más amplio sentido.

¿En qué niveles educativos?; nuestra concepción del problema considera tres etapas ${ }^{\text {it }}$ :

1) En los programas de los ciclos primario y secundario, que podríamos calificar como destinados a la formación humana en general, se observa - y creemos que, sin excepción, en todos nuestros páses - el olvido absoluio, la ausencia, de temas antropológicos (ni biológicos ni cultarables). Parece como si los educadores, pedagogos $y$ administradores del sistema educativo nacional, consideraran que el conocimiento del Hombre es menos importante para el futuro ciudadano que el de los minerfles, plantas, invertebrados o fenómenos físicos, ya que se concede amplio lugar a la Mineralogía, Botánica, Zoología, Física, mientras que la Antropología brilla por su ausencia. No parece necesario que reiteremos una vez más la necesidad de rectificar este olvido y conceder al conocimiento de nuestra propia especie el lugar que le corresponde dentro del marco de adquisiciones culturales que todo niño y todóádoléscented debe efectuar

2) En nivel universitarionhehoso däda Sya pruebas más que suficientes en apoyo de que la Antropología debe ser materia de estudio, como complemento en la formación profesional para médicos, maestros, abogados, ingenieros, arquitectos, etc. - Contamos ya en América Latina con algunos ejemplos alentadores en la Escuela Normal Superior de México; y en esta Universidad Nacional Mayor de San Marcos se ofrecen cursos de iníciación antropológica para los alumnos de Pre-médica y de tercer año de Ciencias. Podrían citarse algunos otros casos. El problema está, por tanto, en la generalización de estas enseñanzas a las otras profesiones donde también resulta indispensable tal conocimiento

14 Comas, Juan. Valor y utilidad de la Antropología fisica en el estudio de las Ciencias Sociales. Acta Americana, vol. 4, pp. 64-81. México, 1946.

Comas, Juan.- Principales contribuciones indígenas precolombinas Antropólogos en Hispanoamérica. Volumen dle Homenaje a AItonso Case, pp. 111-126. México, 1951. 
si su trabajo ulterior va a realizarse entre grupos culturalmente aborígenes o poco aculturados.

3) En último término se trata de la formación de Antropólogos Profesionales en sus distintas especialidades: Etnólogo, Lingüista, Prehistoriador, Arqueólogo, Antropólogo social y Antropólogo físico; a cada una de las cuales corresponde - como hemos intentado mostrar - desempeñar un papel importante en el proceso de Integración Nácional: lo cual significa progreso socio-económico basado en cambios culturales debidamente orientados y controlados.

En ese aspecto conocemos en América Latina distintos ensayos, más o menos logrados. México tiene, desde 1939 (como parte del Instituto Nacional de Antropología e Historía) una Escuela Nacional de Antropología con 4 años de estudios a nivel universitario, donde después de 2 semestres de cursos comunes se orientan los estudiantes hacia une de las 6 especialidades mencionadas. Por lo que se refiere al Perú y concretamente a esta Universidad Nacional Mayor de Sam Marcos, se están dando ya los pasos iniciales necesarios para mejorar y ampliar su actual Departamento de Etnología y Arqueología (con el cual me ha sido dado colaborar durante el año de 1962) en el sentido de transformarlo en un Instituto de Antropología, con lo cual además de convertirse en un organišmó $q$ la vez de docencia e investigación, se ampliaría el marco de sus intereses hoy circunscrito únicamente a dos de las especídidades anfropológicas, Yestándole así visión y enfoque a la interpretación nacional, continental y ecuménica de los problemas planteados. A esto va unido el proyecto de modificación del Curriculum de estudios antropológicos, preparado por el grupo de catediáticos del Departamento y en la actualidad pendiente de estudio por el Consejo de Facultad.

Deseamos fervientemente que muy pronlo sea todo ello tangible realidad.

Es así como concebimos que la Integración Nacional pueda efectuarse en nuestros países, apoyándose sólidamente en la clara idea de la existencia de un Problema Indígena, objetiva y sensatamente orientadio, y de una ciencia antropológica, en la cual deben prepararse técnicos eficientes que el País pueda utilizar en sus justos anhelos de aminorar, mejor suprimir, los desajustes socioeconómicos y lograr, por la aculturación, una total integración a la Peruanidad.

4 de diciembre de 1962. 